\title{
On the Relationship between Inertial Instability, Poleward Momentum Surges, and Jet Intensifications near Midlatitude Cyclones ${ }^{\mathscr{Q}}$
}

\author{
Shellie M. Rowe AND MatThew H. Hitchman \\ Department of Atmospheric and Oceanic Sciences, University of Wisconsin-Madison, \\ Madison, Wisconsin
}

(Manuscript received 4 July 2015, in final form 10 March 2016)

\begin{abstract}
This study explores the role of inertial instability in poleward momentum surges and "flare ups" of the subpolar jet near midlatitude cyclones. Two cases are simulated with the University of Wisconsin Nonhydrostatic Modeling System to investigate the mechanisms involved in jet accelerations downstream of quasi-stationary "digging troughs." Deep convection along the cold front leads to regions of inertial instability in the upper troposphere, which are intimately linked to jet accelerations. Terms in the zonal and meridional wind equations following the motion are evaluated for a selected air parcel within the inertially unstable region. A two-stage synoptic evolution is diagnosed, which is a characteristic signature of inertial instability. First, meridional flow accelerates following the motion, because of the subgeostrophic zonal flow and strong northward pressure gradient force (a statement of inertial instability). Second, supergeostrophic poleward flow leads to zonal acceleration and a jet flare-up. Inertial instability thus effectively displaces a westerly jet maximum poleward relative to inertially stable conditions. The structure of the poleward surge involves a distinctive "head" of high angular momentum, with the region of inertial instability enclosing the jet maximum and a core of strongly negative potential vorticity inside the surge. Departures from angular momentum-conserving profiles during meridional displacement are interpreted in terms of the pressure gradient force and degree of inertial stability. Inertial instability reduces the resulting zonal wind profile relative to angular momentum conservation but provides a significant poleward displacement of the resulting zonal wind maximum.
\end{abstract}

\section{Introduction}

\section{a. History of jet intensifications}

Midlatitude convective storm systems act to exchange properties vertically between the lower and upper troposphere and are important in maintaining the large-scale balance of angular momentum and energy (Palmén and Newton 1969). Eliassen (1959) studied the role of diabatic heating in altering mass circulations. Ninomiya (1971) concluded that thunderstorm outflow

Supplemental information related to this paper is available at the Journals Online website: http://dx.doi.org/10.1175/ JAS-D-15-0183.s1.

Corresponding author address: Shellie M. Rowe, Department of Atmospheric and Oceanic Sciences, University of WisconsinMadison, 1225 W. Dayton St., Madison, WI 53706.

E-mail: rowe1@wisc.edu associated with intense convection aloft was a key dynamical parameter in changing the upper-level flow in the vicinity of intense storm development. Fritsch and Maddox (1981) analyzed the effects of mesoscale convective complexes (MCCs) on synoptic-scale flow and found that latent heating intensified mass circulations in the midtroposphere. Numerous case studies have examined secondary and transverse circulations associated with upper-level jet streaks (Namias and Clapp 1949; Uccellini and Johnson 1979; Shapiro 1981; Kocin et al. 1986). For example, Maddox (1980) inferred that a diabatic component of the isallobaric wind may be significant in areas of intense convection and act to intensify circulations associated with a jet streak. More closely related to the work presented here, Keyser and Johnson (1984) found a connection between jet intensifications and latent heating in an early springtime MCC. They found a $15 \mathrm{~m} \mathrm{~s}^{-1}$ wind speed increase within a jet streak over a 3-6-h time span. Using isentropic coordinates, they found that latent heating in the MCC 
modified the direct mass circulation in the jet entrance region through the forcing of diabatic components of ageostrophic motion.

Research has shown that there is a connection between inertial instability and mesoscale circulations in the atmosphere (Emanuel 1979, 1982). Eliassen (1951) hypothesized that, for a given source of angular momentum, stronger meridional motions develop if the inertial stability of the vortex is weaker. Inertial instability also plays a role in the formation of individual convective cells associated with MCCs (Maddox 1983). Blanchard et al. (1998) used a conceptual model showing how regions of weak uppertropospheric inertial instability can contribute to the upscale growth of the individual cells into MCCs. Mecikalski and Tripoli (2003) proposed that, as convection matures and becomes more organized, it evolves toward a structure that benefits from uppertropospheric inertial instability.

Rowe and Hitchman (2015) focused on the role of inertial instability in facilitating stratospheretroposphere exchange by the "overfold" process. They discussed the production of regions of negative equivalent potential vorticity (EPV) by vortex compression in the upper troposphere. They showed that regions of inertial instability in the dry upper troposphere, as identified by negative regions of EPV or potential vorticity (PV) or absolute vorticity, are nearly identical. In the present work, two of the cases are revisited with a focus on how inertial instability is related to changes in the speed and structure of the subpolar jet. The first case highlights jet intensification associated with a $\sim 500-\mathrm{km}$ poleward displacement of the subpolar jet associated with inertial instability. The second case features "jet flare-ups" that occur in conjunction with smaller regions of inertial instability.

\section{b. Synopsis}

Aspects of angular momentum and inertial instability theory relevant to this work are described in section 2, while section 3 describes the University of Wisconsin Nonhydrostatic Modeling System (UWNMS) simulations. Sections 4 and 5 comprise two representative midlatitude cases in which inertial instability is a key ingredient in jet intensifications and poleward momentum surges. The relationship between regions of inertial instability, absolute momentum, ageostrophic flow, and subsequent jet intensifications will be featured. Case 1 emphasizes a poleward surge of the subpolar jet along with a rapid intensification. Case 2 examines smallerscale jet flare-ups on a weaker subpolar jet. Conclusions are summarized in section 6 .

\section{Inertial instability theory and angular momentum}

Inertial instability occurs when angular momentum decreases radially outward. Conversely, resistance to radial motion occurs when angular momentum increases radially outward. Inertial instability also plays a principal role in the adjustment processes that restore a stable profile of angular momentum. A diagnosis can be made for inertial instability where there are distinctive regions of reversed angular momentum gradients, negative EPV anomalies, or regions of negative absolute vorticity. Distinctive patterns of divergence/convergence and ageostrophic flow also occur in regions of inertial instability. As parcels enter a region of inertial instability, they accelerate, causing divergence, and as they leave such a region, they decelerate, causing convergence. Cross-equatorial flow in the middle atmosphere gives rise to a deep region of inertial instability in the winter subtropics (Dunkerton 1981). Here one may find vertically stacked circulation cells and corresponding layered temperature perturbations or pancake structures as seen in satellite and mesosphere-stratosphere-troposphere radar data, especially when quasi-stationary planetary wave activity is impinging on the subtropical middle atmosphere (Hitchman et al. 1987; Fritts et al. 1992; Hayashi et al. 1998). In the rapidly evolving environment of midlatitude cyclones and embedded convection, inertial instability structures are not usually so well ordered. A summary of inertial instability theory relevant to midlatitude cyclones is given in Rowe and Hitchman (2015). Here the relationship between inertial instability, the horizontal equations of motion, and angular momentum is revisited with a view toward a synoptic description of inertially unstable flow upstream of a ridge.

Although it is traditional to diagnose inertial instability in a linear, Eulerian framework, where meridional advection of zonal flow is grouped with the Coriolis term: $-v \times(f-\partial u / \partial y)$, it proves to be useful to consider the changes of wind following the motion in an inertially unstable region. The zonal and meridional momentum equations for synoptic scaling may be written

$$
\begin{aligned}
& \frac{d u}{d t}=f v-\frac{1}{\rho} \frac{\partial p}{\partial x} \text { and } \\
& \frac{d v}{d t}=-f u-\frac{1}{\rho} \frac{\partial p}{\partial y},
\end{aligned}
$$

where $d / d t=\partial / \partial t+u \partial / \partial x+v \partial / \partial x+w \partial / \partial z$ is the material derivative following the motion, $u$ is zonal flow, $v$ is meridional flow, $\rho$ is density, $p$ is pressure, and $f=$ $2 \Omega \sin \varphi$ is the Coriolis factor. Consider a synoptic situation in the upper troposphere with a jet streak developing northward then eastward around a ridge. First, 
the meridional flow accelerates because of the poleward pressure gradient force overcoming the Coriolis term for weak zonal flow in (1b). As the meridional flow accelerates poleward, the Coriolis term becomes larger than the westward pressure gradient force in (1a), causing eastward zonal flow acceleration. Inertial instability would be expected to excite this sequence.

Starting from (1), traditional presentations of inertial instability in steady sheared zonal geostrophic flow $U$ assume meridional parcel displacements $\delta y$ in the absence of a zonal pressure gradient force, yielding the oscillator-accelerator equation:

$$
\frac{\partial^{2}}{\partial t^{2}} \delta y=-f\left(f-\frac{\partial U}{\partial y}\right) \delta y
$$

with meridional acceleration occurring (inertial instability) if the coefficient is negative: $f(f-\partial U / \partial y)<0$ (Holton 2006). This provides an impetus for poleward acceleration down the pressure gradient, which from (1b) implies that the zonal flow is weaker than geostrophic. Downstream, as the meridional flow accelerates, the Coriolis term leads to acceleration of the zonal flow in (1a).

A generalization of the linear inertial instability criterion for radial parcel displacement $\delta s$ in an axisymmetric vortex yields

$$
\frac{\partial^{2}}{\partial t^{2}} \delta s=-f(f+\zeta) \delta s,
$$

with inertial instability occurring if $f(f+\zeta)<0$, where $\zeta=\partial v / \partial x-\partial u / \partial y$ is relative vorticity (Eliassen and Kleinschmidt 1957). Negative absolute vorticity in the Northern Hemisphere, $\eta=f+\zeta<0$, is a useful criterion for inertial instability. Absolute vorticity is a factor in Ertel's potential vorticity $[\mathrm{PV}=(1 / \rho)(\partial \theta / \partial z)(\zeta+f)]$ and in equivalent potential vorticity [EPV $=$ $(1 / \rho)\left(\partial \theta_{e} / \partial z\right)(\zeta+f)$, where $\theta_{e}$ is equivalent potential temperature]. Rowe and Hitchman (2015) showed that regions where $\eta, \mathrm{PV}$, and EPV are negative coincide almost exactly in the uppermost troposphere.

The distribution of absolute angular momentum can be used to visualize regions of inertial instability and of zonal jet intensification. From the reference frame of Earth's rotation axis, absolute angular momentum per unit mass is given by $m=a \cos \varphi(u+\Omega a \cos \varphi)$, where $a$ is Earth's radius, $\varphi$ is latitude, $\Omega$ is the angular frequency of Earth's rotation, and $u$ is zonal wind speed. The gradient of angular momentum is related to absolute vorticity in the Northern Hemisphere by

$$
-\frac{1}{a \cos \varphi} \frac{\partial m}{\partial y}=f-\frac{1}{\cos \varphi} \frac{\partial}{\partial y}(u \cos \varphi) .
$$

The zonal flow is inertially unstable if (3) is negative, corresponding to a situation where angular momentum increases toward the rotation axis and absolute vorticity is negative.

Consider the implications of conservation of angular momentum in the absence of a zonal pressure gradient force: $d m / d t=0$. A poleward displacement $\delta y$ from latitude 1 to latitude 2, with an initial zonal wind speed of $u_{1}$, will yield a new zonal wind speed of

$$
u_{2}=\Omega a\left(\frac{\cos ^{2} \varphi_{1}-\cos ^{2} \varphi_{2}}{\cos \varphi_{2}}\right)+\frac{\cos \varphi_{1}}{\cos \varphi_{2}} u_{1} .
$$

(Sample curves of constant angular momentum are shown in Fig. 6.) Near $45^{\circ} \mathrm{N}$, a meridional displacement of $1^{\circ}=111 \mathrm{~km}$ will yield a zonal wind speed increase of $\sim 11.6 \mathrm{~m} \mathrm{~s}^{-1}$. From (2a), a region of neutral inertial instability is characterized by $f-\partial u / \partial y=0$, implying a zonal speed increase of $\delta u=f \delta y \approx 11.5 \mathrm{~m} \mathrm{~s}^{-1}$ for a $1^{\circ}$ displacement. This illustrates that curves of neutral inertial stability are also curves of constant angular momentum.

In the absence of a zonal pressure gradient force, one may conclude that zonal wind speed will increase at about $11 \mathrm{~m} \mathrm{~s}^{-1}$ per $1^{\circ}$ of latitude in the midlatitudes. If the region is inertially unstable, poleward displacement will advect weaker zonal winds, reducing the rate of increase expected from angular momentum conservation. That is, subgeostrophic zonal flow is required for poleward acceleration because of inertial instability. If it is inertially stable, stronger zonal winds will be advected poleward so that the rate of increase is greater than angular momentum conserving. A zonal pressure gradient force can radically alter the outcome. A quantitative analysis of the momentum budget along a parcel trajectory within an inertially unstable region is given in section 4.

The ageostrophic component of the wind represents the portion of the flow that is not in geostrophic balance: $u_{a}=u-u_{g}$ and $v_{a}=v-v_{g}$. In most midlatitude cyclones the ageostrophic wind is important in the evolution of temperature and vorticity fields (Holton 2006). Angell (1962) examined trajectory configurations through regions of inertial instability and found evidence that large regions of ageostrophic flows associated with inertial instability are precursors for changes in pressure patterns. He also showed that large deviations in the geostrophic flow occur in and downstream from regions of inertial instability. The distribution of negative absolute vorticity will be compared with the distribution of ageostrophic zonal flow. From the arguments above, one would expect that $u_{a}<0$ and $v_{a}>0$ would result from poleward displacement in an inertially unstable flow. 
Inertial instability leads to spatial variations in accelerations, hence enhanced regions of divergence and convergence and radiation of gravity waves. The atmosphere tends to restore inertial stability and geostrophic balance by generating gravity waves that radiate away and adjust the flow (Rossby 1938; Cahn 1945; Blumen 1972; Van Tuyl and Young 1982; Koch and Dorian 1988, Rowe and Hitchman 2015). Zhang et al. (2000) and McCann (2001) provide overviews of other measures of imbalance. Here, in addition to ageostrophic zonal winds, divergence fields and their relationship with regions of inertial instability will be shown.

Finally, a measure of the importance of the acceleration term relative to the Coriolis term in (1) is provided by the Rossby number $\left(R_{o, u}=|d u / d t| /|f v|, R_{o, v}=|d v / d t| /|f u|\right)$. If the pressure gradient force is closely balanced by the Coriolis term, then Ro is very small. The importance of ageostrophic motions and acceleration increases with increasing Ro. Values of Ro are calculated separately for the zonal and meridional momentum equations along a trajectory as part of the momentum budget analysis.

\section{Simulations and analysis methods}

The two case studies are modeled with UWNMS (Tripoli 1992a,b; Pokrandt et al. 1996; Jascourt 1997; Mecikalski and Tripoli 1998), initialized with $2.5^{\circ}$ European Centre for Medium-Range Weather Forecasts (ECMWF) data. The resolution for both cases is $20 \mathrm{~km} \times 20 \mathrm{~km} \times 300 \mathrm{~m}$, with a grid volume of $152 \times 152 \times 60$ points. The top of the model is set to $16 \mathrm{~km}$, with a $1500-\mathrm{m}$ Rayleigh sponge layer. The side boundary conditions for UWNMS were updated using ECMWF data as the interior domain evolves. Both simulations were initialized $\sim 24 \mathrm{~h}$ before the jet intensifications began and continued for $48 \mathrm{~h}$. Vis5D was used to view the time and 3D structure of each midlatitude cyclone and the associated dynamics in UWNMS.

The model domain for each case is a square with sides of length $3020 \mathrm{~km}$. The center point of the domain is located at $40^{\circ} \mathrm{N}, 95^{\circ} \mathrm{W}$, extending from $26.4^{\circ}$ to $53.6^{\circ} \mathrm{N}$ and from $112.8^{\circ}$ to $77.15^{\circ} \mathrm{W}$. The period 0000 UTC 5 February-0000 UTC 7 February 2008 was simulated for case 1, which focuses on the region extending from the central Mississippi valley through the Great Lakes to southern portions of Ontario and Quebec. The period 0000 UTC 22 April-0000 UTC 24 April 2005 was simulated for case 2 , which focuses on a region including the Ohio valley, eastern Great Lakes, and southern Ontario.

Jet intensification events and associated poleward surges are explored by examining sequences of meridional sections of wind speed, absolute angular momentum, and negative EPV. Sections and plan views of equivalent potential temperature, divergence, and ageostrophic wind will be studied in conjunction with regions of negative EPV and wind speed maxima. Isosurfaces of absolute momentum and negative EPV (looking from east to west), together with plan views at the level of maximum wind speed will be shown. Additional analysis for case 1 includes a detailed momentum budget along a trajectory in the inertially unstable poleward surge. This allows for a comparison between angular momentum-conserving contours (plotted as zonal speed versus latitude) and the evolution of wind speed along this trajectory in the UWNMS. For plotting purposes, angular momentum divided by $a \cos \varphi\left(\mathrm{m} \mathrm{s}^{-1}\right)$ is shown.

\section{Case study 1 (5-6 February 2008)}

\section{a. Poleward surges and jet intensification}

The evolution of winds, angular momentum, and indicators of inertial instability in meridional section for case 1 is shown in Fig. 1. The sequence begins before the jet interacts with inertially unstable air and ends during the time of the farthest poleward extent of a momentum surge. The left-hand column of Fig. 1 shows contours of absolute angular momentum divided by $a \cos \varphi$ (black contours) and regions of strongly negative EPV (color), while the right-hand column shows jet wind speeds (black contours) and negative EPV (color). This time sequence begins at 0820 UTC 5 February 2008 (Fig.1a,b) and depicts a relatively quiet scenario with no inertial instability and a $70 \mathrm{~m} \mathrm{~s}^{-1}$ wind speed maximum located near $44^{\circ} \mathrm{N}$ latitude, $10-\mathrm{km}$ altitude. Moving ahead $10.5 \mathrm{~h}$ to 1900 UTC, as shown in Figs. 1c and 1d, there is an outbreak of negative EPV with values of $-2 \mathrm{PV}$ units $\left(1 \mathrm{PVU}=10^{-6} \mathrm{~K} \mathrm{~kg}^{-1} \mathrm{~m}^{2} \mathrm{~s}^{-1}\right.$ ) over northern Wisconsin. This area of inertial instability coincides with a strong poleward surge of high values of absolute angular momentum. It is evident from Fig. 1c that the $390 \mathrm{~m} \mathrm{~s}^{-1}$ absolute momentum contour has shifted poleward by more than $2^{\circ}$ as a consequence of this inertially unstable situation. In association with this poleward surge of absolute momentum, the jet has intensified to $80 \mathrm{~m} \mathrm{~s}^{-1}$ and moved poleward by $2^{\circ}$ to $46^{\circ} \mathrm{N}$ (Figs.1b,d).

Further intensification takes place over the next $1.5 \mathrm{~h}$ (2040 UTC; Figs. 1e,f). Inertial instability, diagnosed through areas of negative EPV, is now more concentrated within the jet, which is now located over Lake Superior. The region of inertial instability can be readily seen where contours of angular momentum overturn in Figs. 1c, 1e, and $1 \mathrm{~g}$ such that angular momentum increases toward the rotation axis. The region of negative $\mathrm{PV}$ is shown as a heavy dashed contour in Figs. 1d, 1f, and $1 \mathrm{~h}$, encircling the large negative values equatorward of the jet maximum. This poleward rush of high 


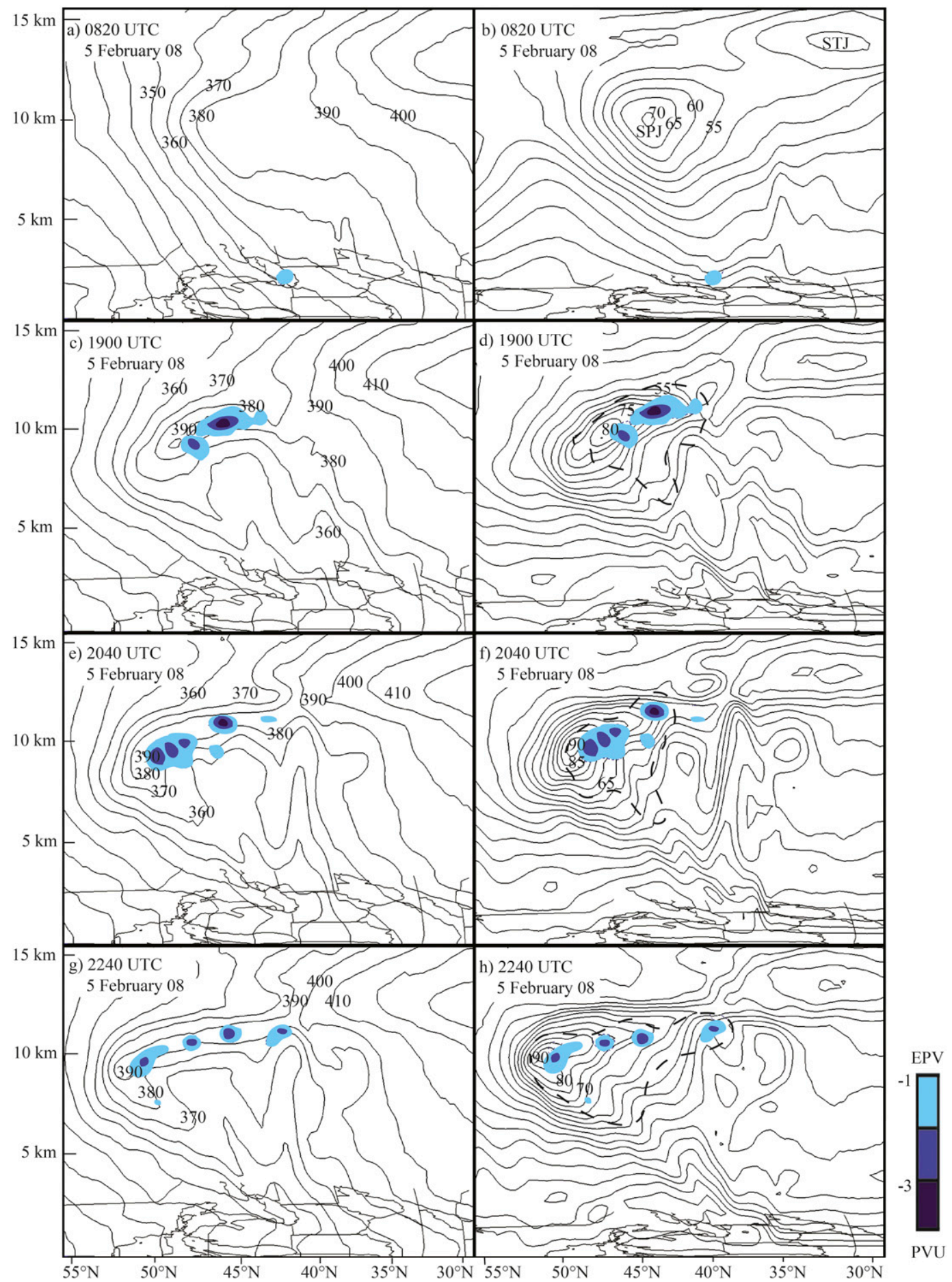

FIG. 1. Evolution of the poleward surge of inertially unstable air as seen in meridional sections along the Mississippi River of (left) angular momentum divided by $a \cos \varphi$ (contour interval: $10 \mathrm{~m} \mathrm{~s}^{-1}$ ) and (right) jet speed (contour interval: $5 \mathrm{~m} \mathrm{~s}^{-1}$ ) during 0820-2240 UTC 5 Feb 2008 in the UWNMS simulation of case 1. Note the progression of the latitude of the jet maximum from (a),(b) $44^{\circ}$ (0830 UTC) to (c),(d) $46^{\circ}$ (1900 UTC) to (e),(f) $48^{\circ}$ (2030 UTC) to (g),(h) $50^{\circ} \mathrm{N}$ (2230 UTC). Regions of strong inertial instability (EPV; color bar) are found embedded in the poleward surge. The relationship between the wind speed maximum and region of inertial instability $(\mathrm{PV}<0$; thick dashed line) is shown in the right column. 
momentum air further intensifies the jet. Figure if shows this intensification and poleward surge as jet wind speeds reach $90 \mathrm{~m} \mathrm{~s}^{-1}$ at $48^{\circ} \mathrm{N}$. This inertially unstable poleward surge has intensified wind speeds by $10 \mathrm{~m} \mathrm{~s}^{-1}$ in only $1.5 \mathrm{~h}$, and the jet has been displaced another $2^{\circ}$ poleward during this time (Fig. 1f).

Figures $1 \mathrm{~g}$ and $1 \mathrm{~h}$ reveal a continued inertially unstable poleward surge. The vault of low angular momentum on the equatorward side of the jet in Figs. 1c, 1e, and $1 \mathrm{~g}$ is produced by convective transport of air having had more recent contact with the ground, creating stronger horizontal wind variations and inertially unstable conditions and facilitating a poleward surge. This is similar to the conclusions reached by Schumacher et al. (2010; cf. their Fig. 17), where negative vorticity near the edge of a convective cell was attributed to low-momentum air being transported upward into juxtaposition with fastermoving air. Another salient aspect of the overall structure of the poleward surge is the vertically narrow region of high-angular-momentum air just above the jet maximum, which becomes more pronounced as the jet pushes $2^{\circ}$ farther poleward by 2240 UTC (Figs. 1g,h).

Over $14 \mathrm{~h}$, the subpolar westerly jet moved poleward by $6^{\circ}$ latitude and increased in speed by $\sim 20 \mathrm{~m} \mathrm{~s}^{-1}$, in association with an inertially unstable poleward momentum surge. Supplemental movie 1 shows the evolution of the jet and its poleward surge for the 48-h simulation. In this sequence, poleward and upward-moving streams of air with EPV $<-2$ PVU are highlighted in dark blue, absolute momentum-conserving contours are shown in black, and the $60 \mathrm{~m} \mathrm{~s}^{-1}$ jet isosurface is shown in transparent white. Assuming a poleward displacement of $6^{\circ}$, if angular momentum were conserved, one would expect an increase of $\sim 66 \mathrm{~m} \mathrm{~s}^{-1}$ (section 2). Pure conservation of angular momentum does not consider the effects of the zonal pressure gradient force on wind speed upon poleward displacement. A more detailed analysis of the momentum budget is given in the next subsection.

We next focus on the period of rapid intensification and the relationship between isosurfaces of angular momentum and negative EPV. Figure 2 shows the $350 \mathrm{~m} \mathrm{~s}^{-1}$ angular momentum isosurface (divided by $a \cos \varphi$ ) colored by wind speed, together with isosurfaces of negative EPV in green, as viewed from the east. The $350 \mathrm{~m} \mathrm{~s}^{-1}$ angular momentum surface is indicated in blue for wind speeds below $50 \mathrm{~m} \mathrm{~s}^{-1}$, while red indicates wind speeds above $60 \mathrm{~m} \mathrm{~s}^{-1}$. The time sequence, which starts at 2000 UTC 5 February 2008 and ends at 0330 UTC 6 February 2008, suggests that, as the anomalous areas of negative EPV (-2-PVU green isosurfaces) move poleward, a distinct increase in jet wind speed (red shading) occurs, along with a poleward displacement of this isosurface of angular momentum. At 2000 UTC (Fig. 2a), the region of inertial

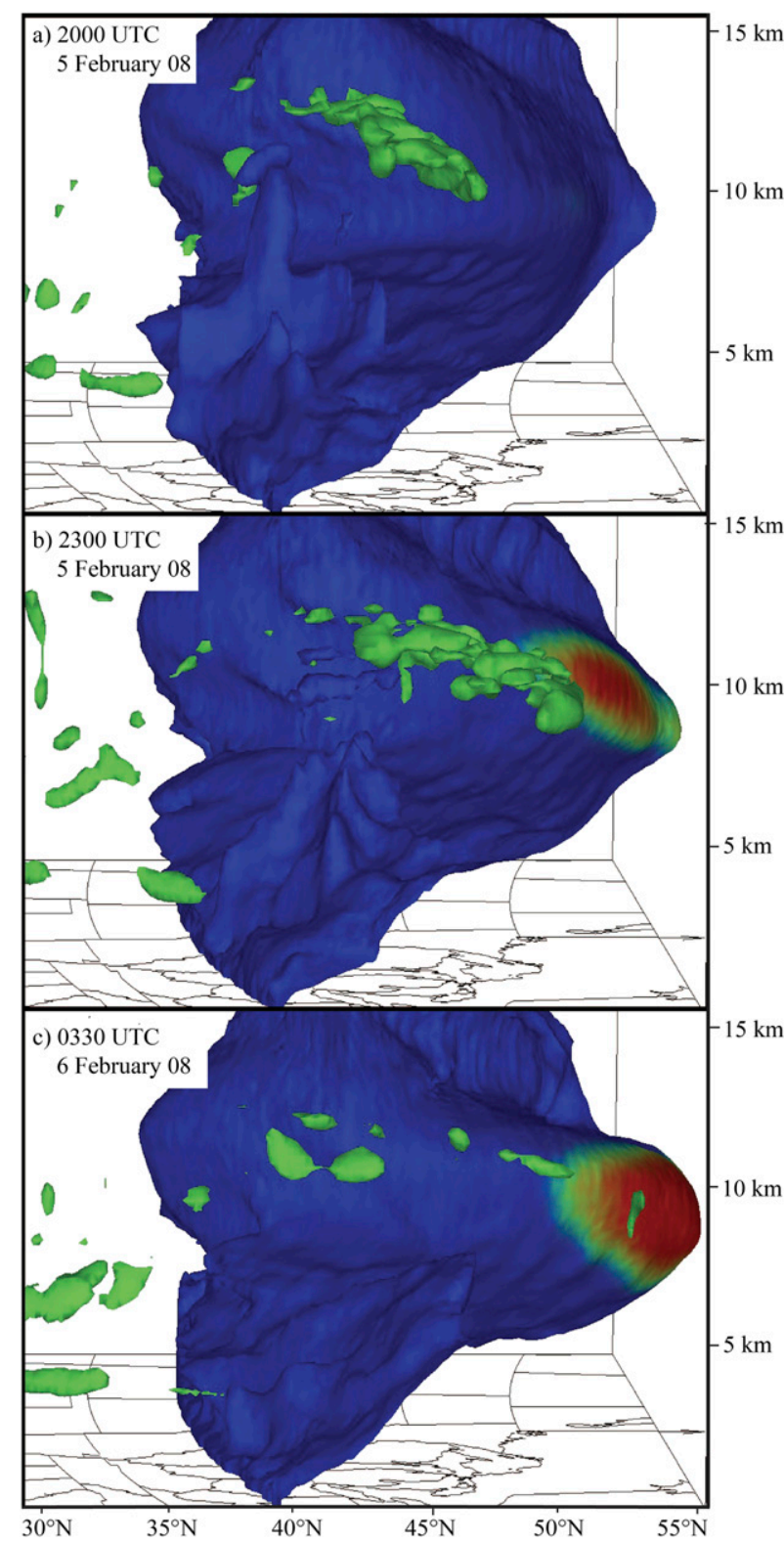

FIG. 2. Evolution of the poleward momentum surge from (a) 2000 UTC 5 Feb to (b) 2300 UTC 5 Feb to (c) 0330 UTC 6 Feb 2008 , as seen from the east. Poleward deformation of the $350 \mathrm{~m} \mathrm{~s}^{-1}$ angular momentum isosurface (divided by $a \cos \varphi$ and shaded by wind speed; blue indicates $<50 \mathrm{~m} \mathrm{~s}^{-1}$; red indicates $>62 \mathrm{~m} \mathrm{~s}^{-1}$ ) coincides with a poleward surge of inertially unstable air, the core of which exceeds -2 PVU (green isosurface).

instability is close to the $350 \mathrm{~m} \mathrm{~s}^{-1}$ angular momentum isosurface (cf. Figs. 1e,f), with a layer of highly negative EPV approaching the $350 \mathrm{~m} \mathrm{~s}^{-1}$ isosurface on the equatorward side (green isosurface). At this time, wind speeds on the $350 \mathrm{~m} \mathrm{~s}^{-1}$ isosurface do not yet exceed $50 \mathrm{~m} \mathrm{~s}^{-1}$.

Three hours later, at 2300 UTC (Fig. 2b), the $350 \mathrm{~m} \mathrm{~s}^{-1}$ isosurface is bulging poleward as the -2-PVU 


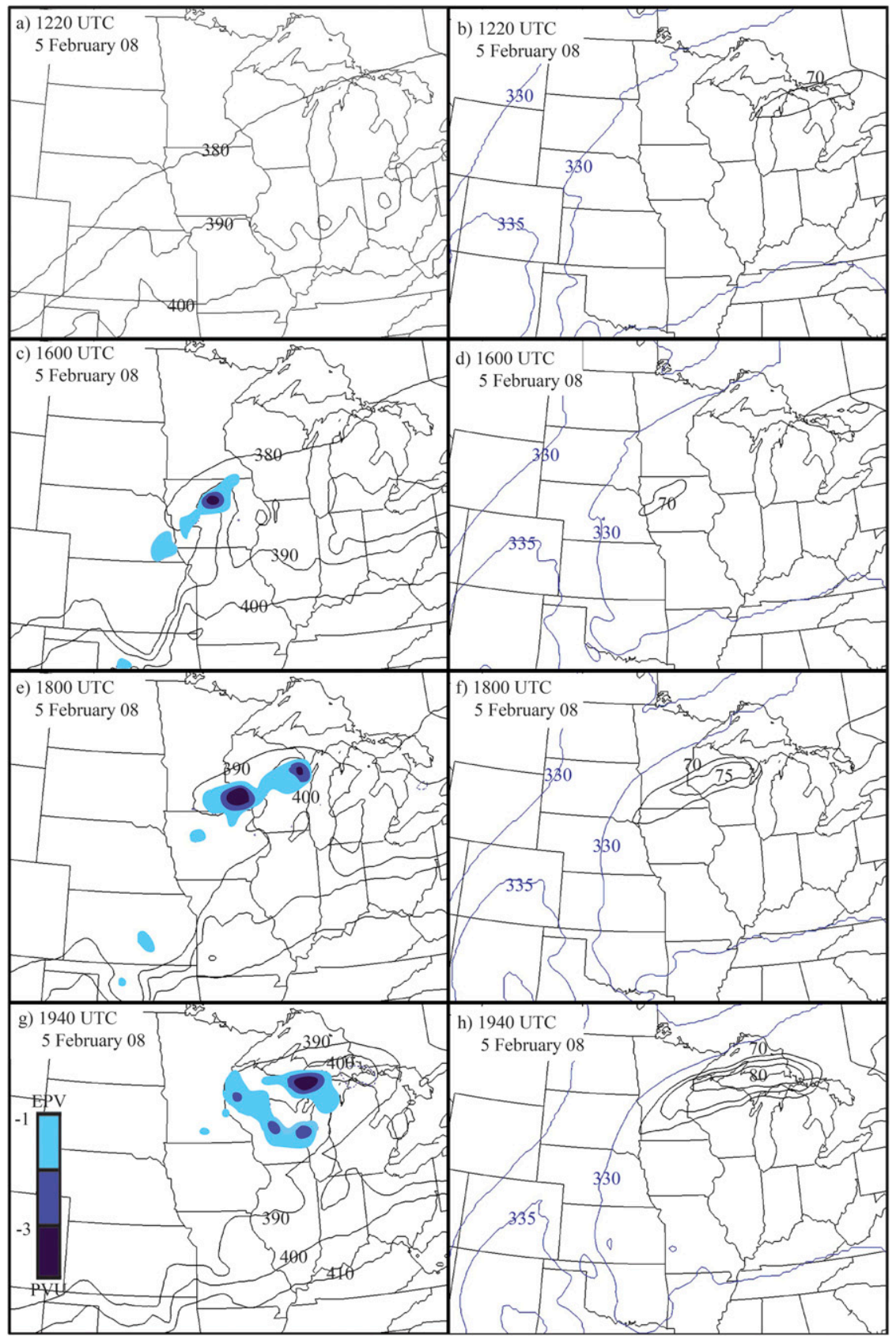

FIG. 3. Evolution of the poleward surge at 10-km altitude during 1220-1940 UTC 5 Feb 2008. (a),(c),(e),(g) Negative EPV (color bar; PVU) and absolute angular momentum divided by $a \cos \varphi$ (black contours; every $10 \mathrm{~m} \mathrm{~s}^{-1}$ in the range $380-410 \mathrm{~m} \mathrm{~s}^{-1}$ ). (b),(d),(f),(h) Wind speed (black contours; every $5 \mathrm{~m} \mathrm{~s}^{-1}$ in the range $70-80 \mathrm{~m} \mathrm{~s}^{-1}$ ) and equivalent potential temperature (blue contours at 330 and $335 \mathrm{~K}$ only).

regions approach this isosurface, consistent with the change in position of the $350 \mathrm{~m} \mathrm{~s}^{-1}$ momentum contour from Fig. 1e to Fig. 1g. In association with this inertially unstable poleward surge, the $65 \mathrm{~m} \mathrm{~s}^{-1}$ jet is now evident on this surface of momentum (red in Fig. 2b). By 0330 UTC 6 February 2008 (Fig. 2c), the region of high angular momentum and high wind speed has continued to grow and expand poleward in the northeastern corner of the domain. This poleward bulge of the $350 \mathrm{~m} \mathrm{~s}^{-1}$ contour is also evident in supplemental movie 1.

Figures 3-5 illustrate the relationship among wind speed, inertial instability, potential temperature, and 


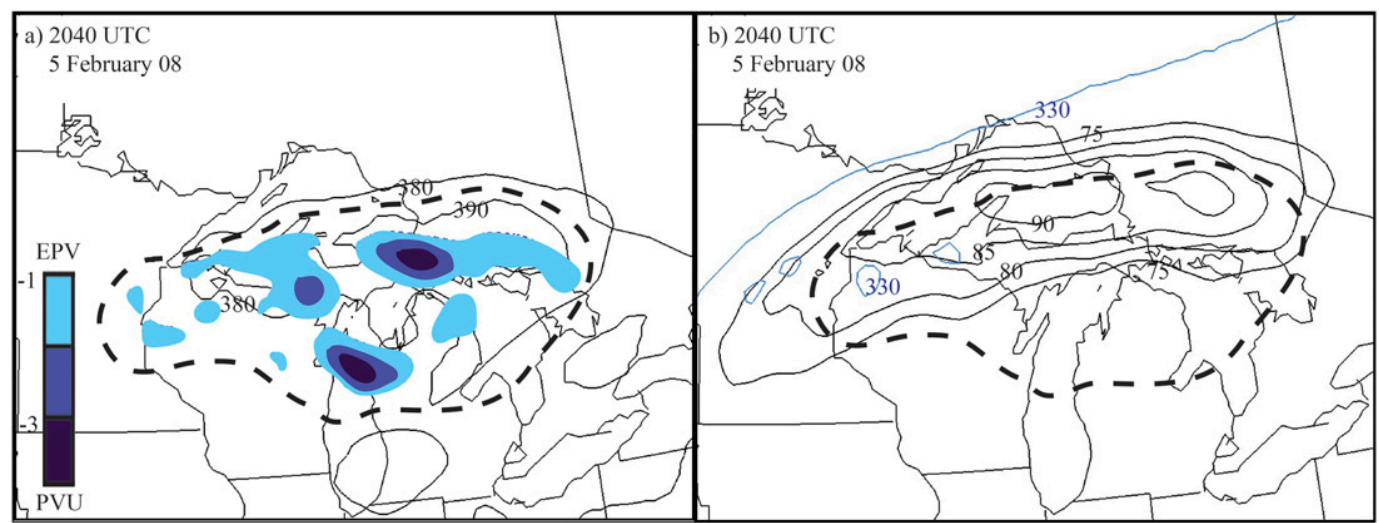

FIG. 4. As in Fig. 3, but focusing on the Great Lakes region near the level of the subpolar jet maximum (10 km), at 2040 UTC 5 Feb 2008. The region of inertial instability (EPV < 0 PVU) is highlighted with a thick dashed line.

ageostrophic wind. Figure 3 shows plan views at $10 \mathrm{~km}$ of angular momentum and strongly negative EPV (left), together with $\theta_{e}$ and jet speed (right) during 1220-1940 UTC 5 February 2008. At 1220 UTC (Figs. 3a,b), there are no regions of strong inertial instability, and a small $70 \mathrm{~m} \mathrm{~s}^{-1}$ jet core is found over northern Lake Michigan and northern Lake Huron. During the poleward surge, note the strong spatial correlation between the region of negative EPV and wind speed (Figs. 3c-h). The highest jet wind speeds in Fig. 3d appear over Iowa near the head of the poleward surge of inertially unstable air and then strengthen as the jet streak moves northeastward through Wisconsin (Fig. 3f) to the Upper Peninsula of Michigan (Fig. 3h). This supports the hypothesis that poleward-moving, inertially unstable air displaces the

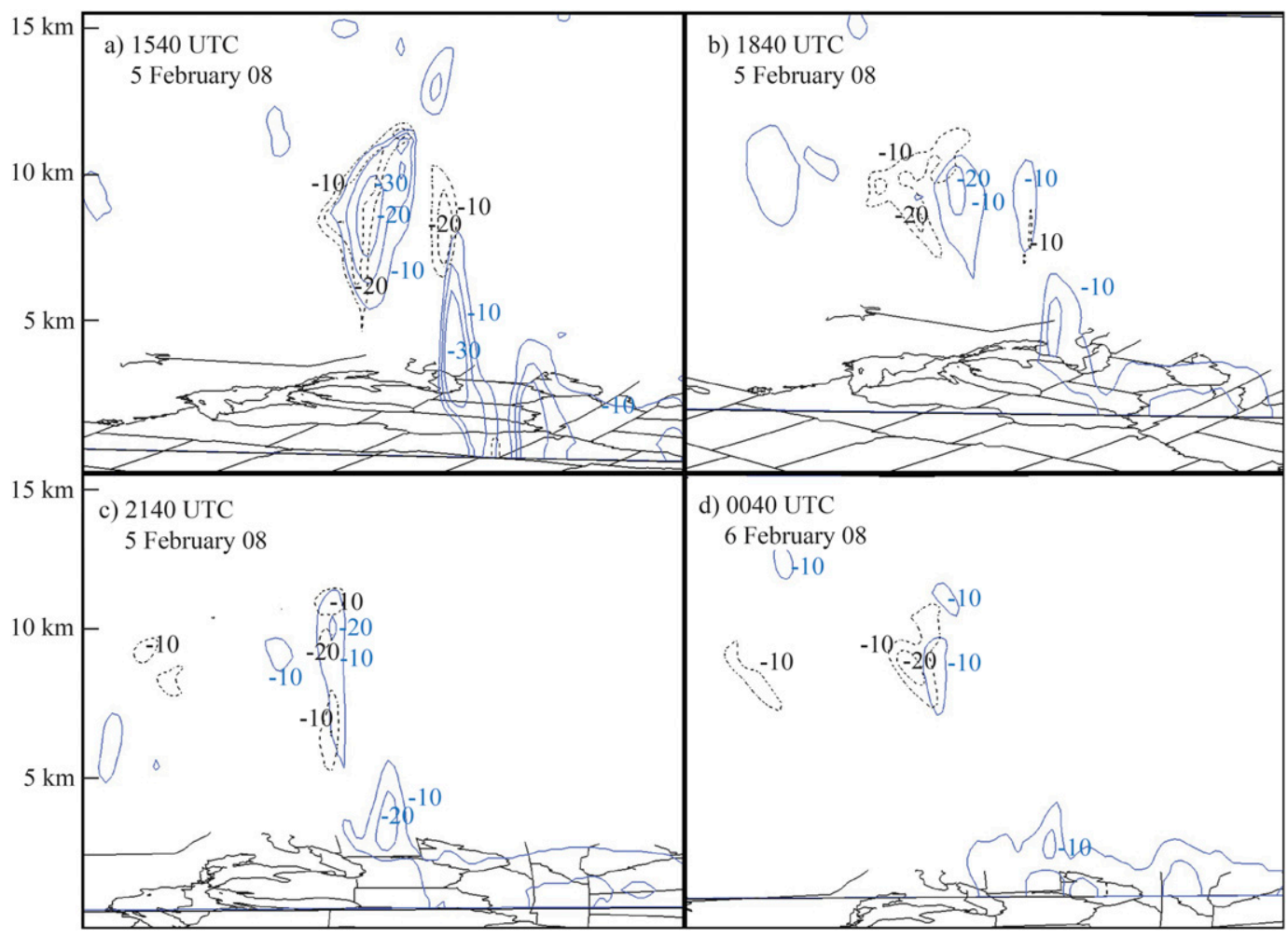

FIG. 5. Meridional sections of negative absolute vorticity (dashed black contours; interval: $10 \times 10^{-5} \mathrm{~s}^{-1}$ ), and ageostrophic zonal wind (solid blue contours; interval: $10 \mathrm{~m} \mathrm{~s}^{-1}$ ) along the path of the parcel trajectory shown in Fig. 6 are shown for (a) 1540, (b) 1840, and (c) 2140 UTC 5 Feb and (d) 0040 UTC 6 Feb 2008. 


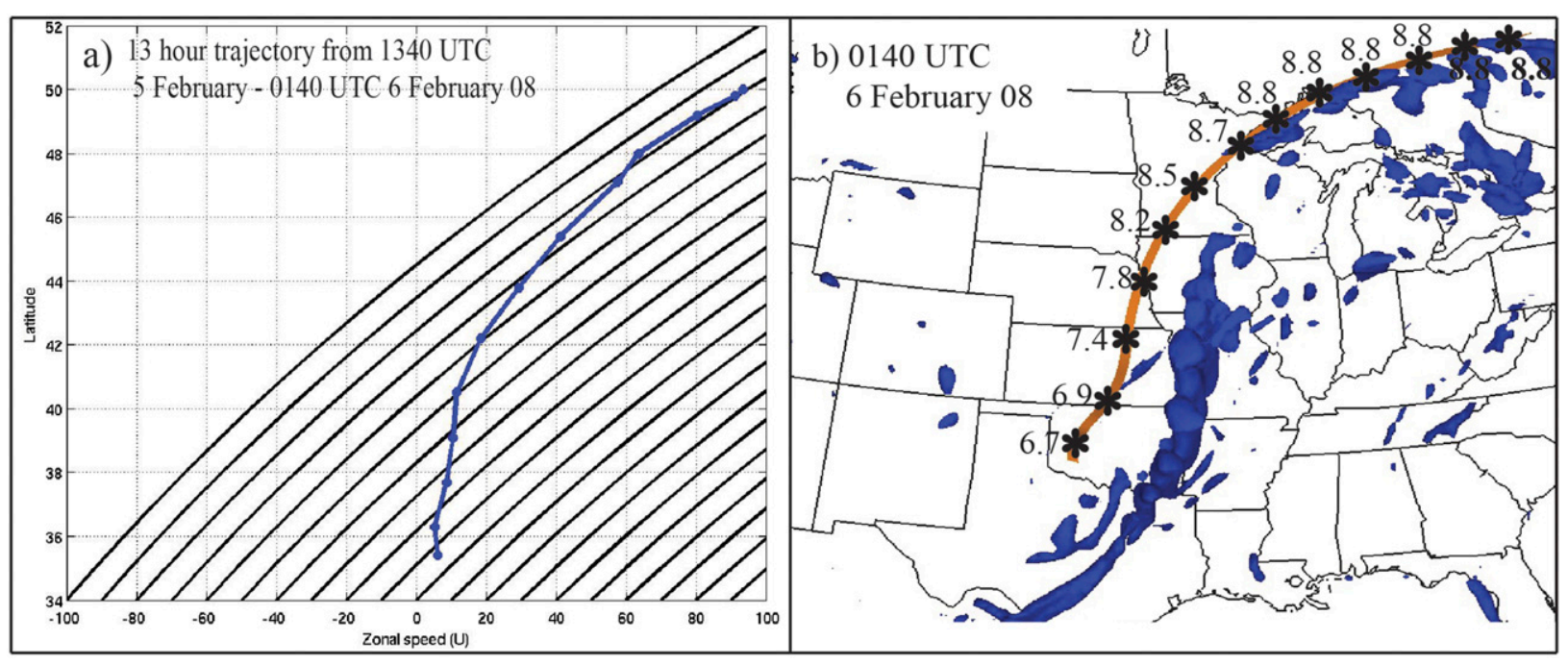

FIG. 6. (a) Comparison of zonal wind speed changes during 1340 UTC 5 Feb-0140 UTC 6 Feb 2008 in the poleward surge following a parcel trajectory with absolute vorticity less than $-8 \times 10^{-5} \mathrm{~s}^{-1}$, superimposed on contours of constant angular momentum (starting with a range of zonal velocities initialized at $34^{\circ} \mathrm{N}$ every $10 \mathrm{~m} \mathrm{~s}^{-1}$ ). (b) Horizontal path of trajectory, with position and altitude (km) shown every hour, along with the instantaneous distribution of the $-8 \times 10^{-5} \mathrm{~s}^{-1}$ absolute vorticity isosurface (blue) at 0140 UTC 6 Feb. The relatively small zonal displacement between the trajectory and instantaneous negative PV streamer over $13 \mathrm{~h}$ indicates that the storm is moving slowly.

westerly jet maximum poleward relative to where it would be in the absence of inertial instability.

By 2040 UTC, the poleward surge reached Lake Superior, with jet speeds increasing to $90 \mathrm{~m} \mathrm{~s}^{-1}$ (Fig. 4b). The inertially unstable region (thick dashed line) encloses an air mass with normalized momentum values exceeding $380 \mathrm{~m} \mathrm{~s}^{-1}$ and regions of negative EPV exceeding -3 PVU (Fig. 4a). The inertially unstable region encompasses the jet speed maximum and the equatorward side of the jet (Fig. 4b). Values of $\theta_{e}$ are fairly uniform near $330 \mathrm{~K}$ (Fig. 4b). This horizontal view of the structure of a jet streak lying at the poleward edge of an inertially unstable region complements the meridional sections in Figs. 1 and 2.

Convective updrafts that create the inertially unstable regions in the upper troposphere exhibit a distinctive relationship between negative absolute vorticity and subgeostrophic zonal flow. The collocation of negative absolute vorticity and negative ageostrophic zonal wind, calculated as $u_{a}=u-u_{g}$, is shown in a sequence of latitude-altitude sections in Fig. 5, with locations and times corresponding to the trajectory shown in Figs. 6 and 7. In each of the four panels, negative ageostrophic zonal flow coincides with regions of negative absolute vorticity. The ageostrophic zonal component of the wind is in the range from -10 to $-30 \mathrm{~m} \mathrm{~s}^{-1}$ in the strongly inertially unstable regions where absolute vorticity is in the range from -10 to $-30 \times 10^{-5} \mathrm{~s}^{-1}$. This is in agreement with the discussion of Lagrangian changes along the path following (1). In an inertially unstable region, poleward motion in strong positive meridional wind shear will simply advect lower zonal wind values poleward, reducing the zonal flow relative to geostrophic values, ensuring subgeostrophic zonal flow.

\section{b. Lagrangian momentum budget and conservation of angular momentum}

To investigate how inertial instability leads to poleward surges and jet flare-ups, a specific air parcel is chosen, which maintained absolute vorticity values less than $-8 \times 10^{-5} \mathrm{~s}^{-1}$ along a trajectory that arrived at the most poleward location during the surge at 0140 UTC 6 February 2008. The meridional profile of zonal wind speed, trajectory, and the $-8 \times 10^{-5} \mathrm{~s}^{-1}$ absolute vorticity isosurface at the ending time of the trajectory are shown in Fig. 6, while charts of pressure, meridional, and zonal wind speeds at altitudes corresponding to the trajectory are shown in Fig. 7.

The solid curves in Fig. 6a illustrate how the speed of air parcels increases under latitudinal displacement, given the assumptions in section 2: conservation of angular momentum in an inviscid environment with no zonal pressure gradient force. The starting latitude is $34^{\circ} \mathrm{N}$ with an initial range of zonal wind speeds. Asterisks in Fig. 6b labeled with altitude $(\mathrm{km})$ are superimposed on the trajectory to indicate the hourly position of the air parcel during this $13-\mathrm{h}$ period. The small zonal displacement between the trajectory and the instantaneous negative PV streamer (Fig. 6b) indicates that the storm is slowly evolving during this time. 


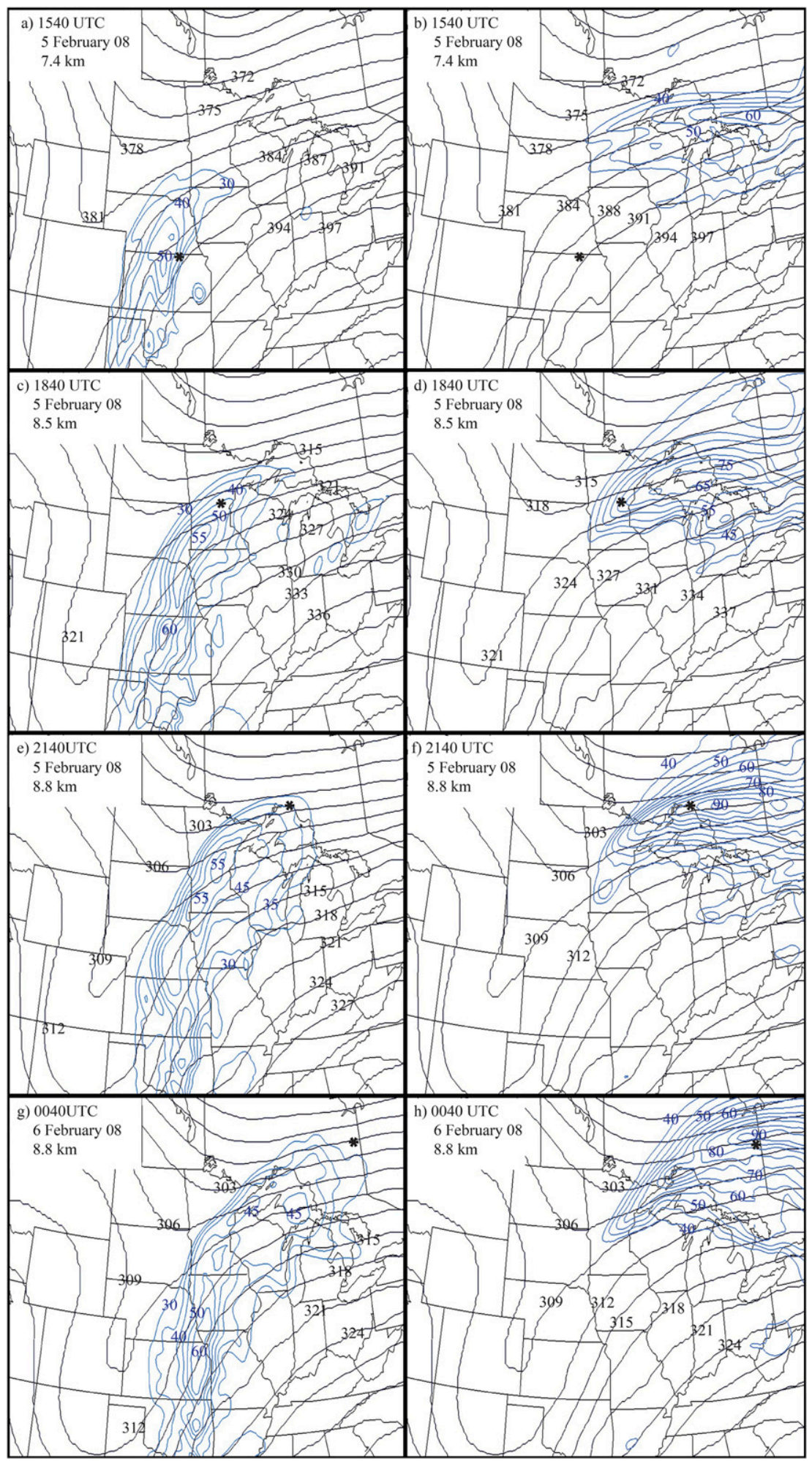

FIG. 7. Synoptic evolution of pressure (black contours every $3 \mathrm{hPa}$ ) together with (left) meridional wind speed (blue contours every $5 \mathrm{~m} \mathrm{~s}^{-1}$ above $30 \mathrm{~m} \mathrm{~s}^{-1}$ ) and (right) zonal wind speed (blue contours every $5 \mathrm{~m} \mathrm{~s}^{-1}$ above $40 \mathrm{~m} \mathrm{~s}^{-1}$ ) during the inertially unstable poleward surge: (a),(b) 1540, (c),(d) 1840, and (e),(f) 2140 UTC 5 Feb and (g),(h) 0040 UTC 6 Feb 2008. The position of the parcel along the trajectory in Fig. 6 is indicated by an asterisk; the corresponding altitude for each pressure chart is indicated. First the meridional flow accelerates in a poleward surge, and then the zonal flow accelerates in a jet flare-up. 
TABLE 1. Estimation of terms in the zonal and meridional momentum budgets following the trajectory shown in Figs. 6 and 7 for case 1 . Here, $d / d t$ corresponds to the sum of the local pressure gradient force and Coriolis effect, while $\delta / \delta t$ corresponds to changes seen following the parcel.

\begin{tabular}{|c|c|c|c|c|}
\hline & \multicolumn{4}{|c|}{ Time (UTC) } \\
\hline & 1540 & 1840 & 2140 & 0400 \\
\hline$u\left(\mathrm{~m} \mathrm{~s}^{-1}\right)$ & 8.6 & 18.4 & 58.0 & 91.0 \\
\hline$v\left(\mathrm{~m} \mathrm{~s}^{-1}\right)$ & 40.0 & 53.0 & 49.1 & 21.0 \\
\hline$f v\left(\mathrm{~m} \mathrm{~s}^{-2}\right)$ & $3.5 \times 10^{-3}$ & $5.2 \times 10^{-3}$ & $5.3 \times 10^{-3}$ & $2.3 \times 10^{-3}$ \\
\hline$-\frac{1}{\rho} \frac{\Delta P}{\Delta x}\left(\mathrm{~m} \mathrm{~s}^{-2}\right)$ & $-2.9 \times 10^{-3}$ & $-2.1 \times 10^{-3}$ & $-3.1 \times 10^{-4}$ & $-5.4 \times 10^{-4}$ \\
\hline$\frac{d u}{d t}\left(\mathrm{~m} \mathrm{~s}^{-2}\right)$ & $5.8 \times 10^{-4}$ & $3.0 \times 10^{-3}$ & $4.7 \times 10^{-3}$ & $1.8 \times 10^{-3}$ \\
\hline$\frac{\delta u}{\delta t}\left(\mathrm{~m} \mathrm{~s}^{-2}\right)$ & $7.3 \times 10^{-4}$ & $2.5 \times 10^{-3}$ & $3.1 \times 10^{-3}$ & $1.8 \times 10^{-3}$ \\
\hline$R_{o, u}$ & 0.2 & 0.5 & 0.6 & 0.8 \\
\hline$-f u\left(\mathrm{~m} \mathrm{~s}^{-2}\right)$ & $-7.7 \times 10^{-4}$ & $-1.8 \times 10^{-3}$ & $-6.2 \times 10^{-3}$ & $-1.0 \times 10^{-2}$ \\
\hline$-\frac{1}{\rho} \frac{\Delta P}{\Delta y}\left(\mathrm{~m} \mathrm{~s}^{-2}\right)$ & $4.1 \times 10^{-3}$ & $7.2 \times 10^{-3}$ & $9.5 \times 10^{-3}$ & $1.0 \times 10^{-2}$ \\
\hline$\frac{d v}{d t}\left(\mathrm{~m} \mathrm{~s}^{-2}\right)$ & $3.3 \times 10^{-3}$ & $5.4 \times 10^{-3}$ & $3.3 \times 10^{-3}$ & $-4.0 \times 10^{-5}$ \\
\hline$\frac{\delta v}{\delta t}\left(\mathrm{~m} \mathrm{~s}^{-2}\right)$ & $1.4 \times 10^{-3}$ & $1.1 \times 10^{-3}$ & $-1.4 \times 10^{-3}$ & $-2.5 \times 10^{-3}$ \\
\hline$R_{o, v}$ & 1.8 & 0.6 & 0.2 & 0.2 \\
\hline
\end{tabular}

The trajectory of this air parcel began several hours earlier in the boundary layer over Texas (not shown), with convective transport to $6.7-\mathrm{km}$ altitude by 1340 UTC, the first of the plotted locations in Fig. 6. Over the next $3 \mathrm{~h}$, the parcel ascended with a vertical motion $w \sim$ $10 \mathrm{~cm} \mathrm{~s}^{-1}$, diminishing to $\sim 2 \mathrm{~cm} \mathrm{~s}^{-1}$ over the next $3 \mathrm{~h}$, with nearly level flow at $8.8 \mathrm{~km}$ for the remainder of the trajectory. This suggests that vertical advection of zonal momentum, $-w \partial u / \partial z$, would be a significant component of an Eulerian momentum budget. However, by considering acceleration following the motion [see (1)], individual advection terms need not be calculated. During the 13 -h trajectory from $35.5^{\circ}$ to $50^{\circ} \mathrm{N}$, this parcel's zonal speed increased from 6 to $91 \mathrm{~m} \mathrm{~s}^{-1}$, a gain of $85 \mathrm{~m} \mathrm{~s}^{-1}$. This may be compared with an expected increase of $\sim 160 \mathrm{~m} \mathrm{~s}^{-1}$ from conservation of angular momentum for this $14.5^{\circ}$ latitudinal displacement. The first half of the trajectory occurred in the presence of weak zonal flow and an accelerating meridional flow, consistent with a strong westward zonal pressure gradient force and a strong northward pressure gradient force.

The solid curves in Fig. 6a correspond to inertially neutral flow, where $f=\partial u / \partial y$. Perhaps counterintuitively, under conditions of inertial instability the meridional flow accelerates, but $f-\partial u / \partial y<0$, so the meridional increase of zonal wind upon meridional displacement is expected to lag behind the angular momentum-conserving profiles. That is, zonal flow acceleration is reduced by inertial instability in poleward displacement! Conversely, in conditions of strong inertial stability, $f-\partial u / \partial y>0$, so the meridional increase of zonal wind would exceed that of angular momentum-conserving profiles. It is also clear in this situation that the zonal pressure gradient force acted to reduce the gain of zonal wind speed during northward displacement, relative to angular momentum-conserving flow in the first half of the trajectory.

Quantitative estimates of terms in the Lagrangian momentum budget along this trajectory, for the zonal and meridional wind components in (1), are provided in Table 1. Relevant parameters, including zonal and meridional wind speed, were sampled along the trajectory every hour for $13 \mathrm{~h}$. Four points along the path were chosen for evaluating the momentum budget: 1540, 1840, and 2040 UTC 5 February and 0140 UTC 6 February. Changes of zonal and meridional wind speed along the path, $\delta u / \delta t$ and $\delta v / \delta t$, were evaluated by centered differencing $(\delta t=2 \mathrm{~h})$. Components of the pressure gradient force were evaluated from the synoptic charts for the appropriate altitude, which are shown in Fig. 7. Density was estimated using $\rho=\rho_{o} e^{-z / H}$, with $H=7.5 \mathrm{~km}$ and $\rho_{o}=1.2 \mathrm{~kg} \mathrm{~m}^{-3}$. Variation of the Coriolis parameter was significant, increasing by $\sim 20 \%$ from $35.5^{\circ}$ to $50^{\circ} \mathrm{N}$.

Figure 7 shows the synoptic sequence of 1) poleward acceleration (in the presence of inertial instability) during the first half of the trajectory, followed by 2) a rapid increase in zonal flow, or jet flare-up, during the second half of the trajectory. This sequence shows how anticyclonic structures can be shaped by inertial instability and provides a contribution toward understanding how air can enter a confluence zone. Sutcliffe (1938) and Namias and 


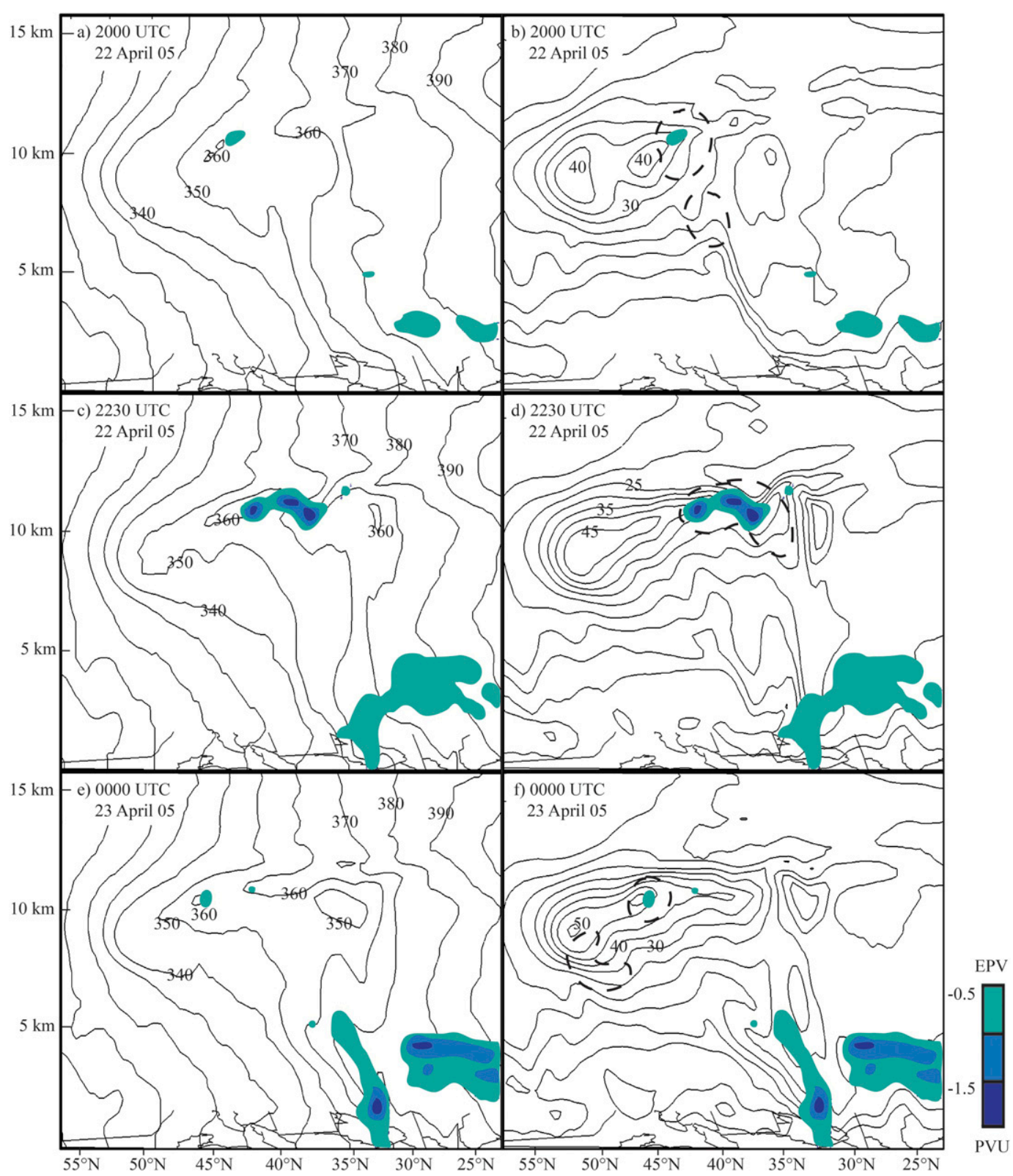

FIG. 8. As in Fig. 1, but for case 2 at (a),(b) 2000 and (c),(d) 2230 UTC 22 Apr and (e),(f) 0000 UTC 23 Apr 2005.

Clapp (1949) argued that confluence in the upper troposphere requires flow toward lower pressure with acceleration into the confluence region. Inertial instability associated with convection equatorward of the jet entrance region specifically promotes this process.

In the first half of the trajectory, the meridional wind accelerates to $\sim 53 \mathrm{~m} \mathrm{~s}^{-1}$ (Table 1) because of the imbalance of a strong poleward pressure gradient force versus a small Coriolis term. This is because of weak zonal flow imposed by convective updrafts and is a synoptic signature of inertial instability (Fig. 7). During these $13 \mathrm{~h}$, the zonal wind speed increases from $\sim 9$ to $\sim 91 \mathrm{~m} \mathrm{~s}^{-1}$, with much more rapid increase in the second half of the trajectory (Table 1 ). The sum $f v-(1 / \rho)(\partial p / \partial x)=d u / d t$ agrees reasonably well with estimates of acceleration along the path $\delta u / \delta t$ (Table 1 ). The general trend of $\delta v / \delta t$ with time along the trajectory agrees with the general trend in the sum $-f v+(1 / \rho)(\partial p / \partial y)=d v / d t$, with poleward acceleration at the first quarter of the trajectory, followed by deceleration and a maximum meridional speed during midtrajectory, as depicted in Fig. 7. But there are significant discrepancies between the observed and theoretical estimates of meridional wind acceleration. This may be due 
to a time delay between when conditions favor acceleration and how long it takes to accelerate. This asymmetry in agreement for the zonal and meridional momentum budgets may be due to inertial instability, which favors meridional acceleration in this case. The presence of robust gravity wave features along the trajectory can also influence local acceleration, as sampled by finite differencing.

The Rossby number was calculated separately for the zonal and meridional momentum equations. Results in Table 1 show that $R_{o, u}$ for the zonal wind equation increased from 0.2 to 0.8 , and $R_{o, v}$ for the meridional wind equation decreased from 1.8 to 0.2 . This is consistent with a primary causal agent, inertial instability, identified with strong ageostrophic meridional acceleration, which gradually comes into geostrophic balance over the next $13 \mathrm{~h}$. This is the poleward surge stage of synoptic flow evolution (Fig. 7, left). During this stage, zonal flow acceleration is weak, and $R_{o, u}$ is small. During the second phase of synoptic development (Fig. 7, right), the jet flare-up stage, the zonal flow is accelerating because of the Coriolis torque on strong meridional wind into the confluence zone characterized by a very weak zonal pressure gradient force, and $R_{o, u}$ is correspondingly larger.

\section{Case study 2 (22 April 2005) -Jet flare-ups related to inertial instability}

Although the model domain is the same, the area of interest in case 2 is just east of Lake Huron, over southern Ontario and the Ohio valley. As in Fig. 1, the left-hand column of Fig. 8 shows contours of absolute angular momentum (black contours) and negative EPV (color bar), while the right-hand column shows jet wind speeds (black contours), negative EPV (thick dashed line) and strongly negative EPV (color bar). Figure 8 begins at 2000 UTC 22 April 2005, during the jet intensification process, and ends at 0000 UTC 23 April 2005, at the time of greatest poleward displacement.

At 2000 UTC (Figs. 8a,b), a split jet with maximum wind speeds near $40 \mathrm{~ms}^{-1}$ is observed, with little indication of inertial instability in the form of either negative EPV or folded angular momentum contours. Yet the signature of poleward deformation of angular momentum contours is clear at this time. Just $2.5 \mathrm{~h}$ later (Figs. 8c,d), one observes the outbreak of an inertially unstable region near $11 \mathrm{~km}$ over southern Ontario and the Ohio River valley. The $360 \mathrm{~m} \mathrm{~s}^{-1}$ angular momentum contour has moved $1^{\circ}$ poleward, along with the wind speed maximum, which now exceeds $\sim 45 \mathrm{~m} \mathrm{~s}^{-1}$. By 0000 UTC 23 April 2005, $1.5 \mathrm{~h}$ later, the $360 \mathrm{~m} \mathrm{~s}^{-1}$ contour and jet maximum have moved poleward another

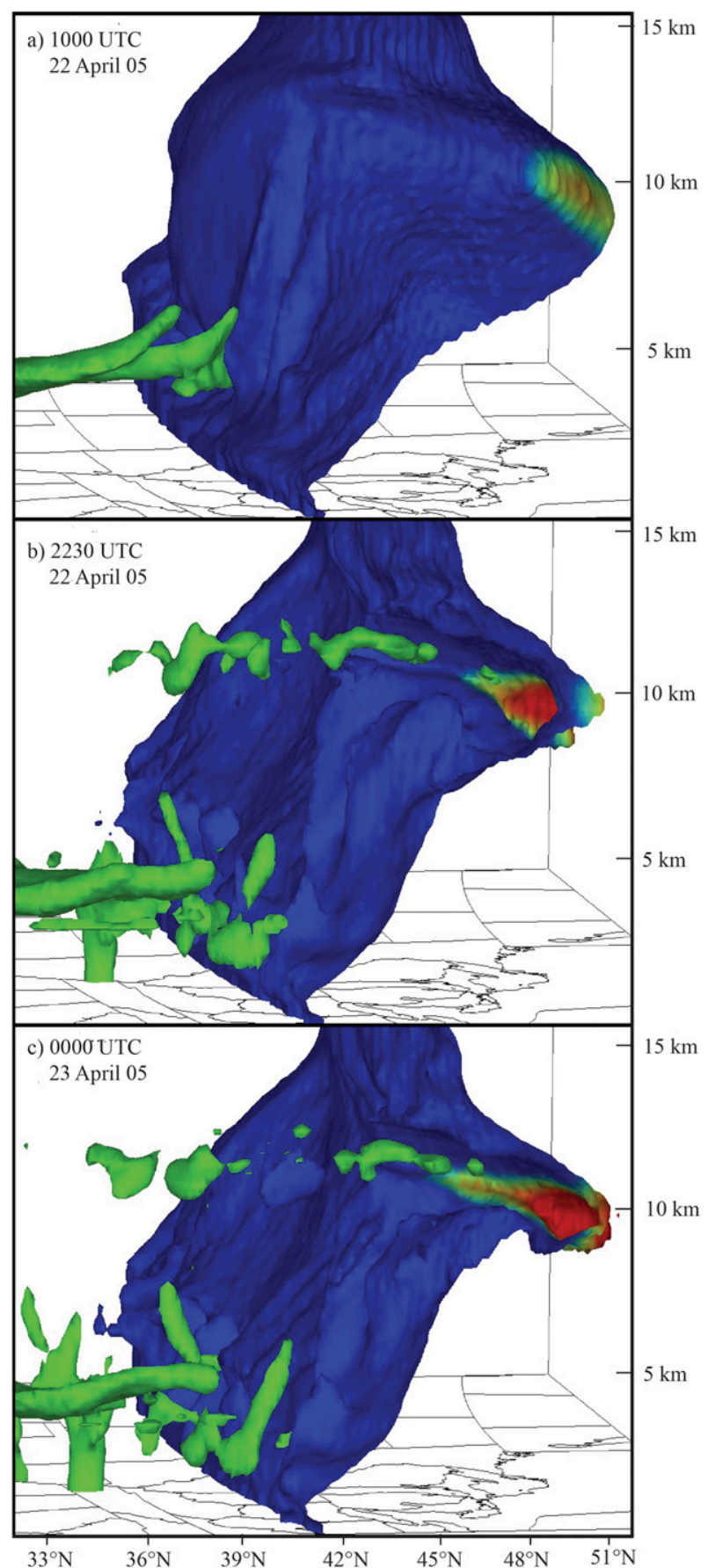

FIG. 9. As in Fig. 2, but for case 2 at (a) 1000 UTC 22 Apr, (b) 2230 UTC 22 Apr, and (c) 0000 UTC 23 Apr 2005. Air with strong inertial instability ( $-1-P V U$ green isosurface) coincides with poleward deformation of the $350 \mathrm{~m} \mathrm{~s}^{-1}$ angular momentum isosurface (divided by $a \cos \varphi$ ), shaded by wind speed (blue indicates $<45 \mathrm{~m} \mathrm{~s}^{-1}$; red indicates $>45 \mathrm{~m} \mathrm{~s}^{-1}$ ).

$0.5^{\circ}$, and the wind maximum has increased to $50 \mathrm{~m} \mathrm{~s}^{-1}$. The poleward surge of the jet in case 2 is not as strong as in case 1 , with the jet moving poleward by $\sim 1.5^{\circ}$ in $4 \mathrm{~h}$, although dynamical similarity is evident. 


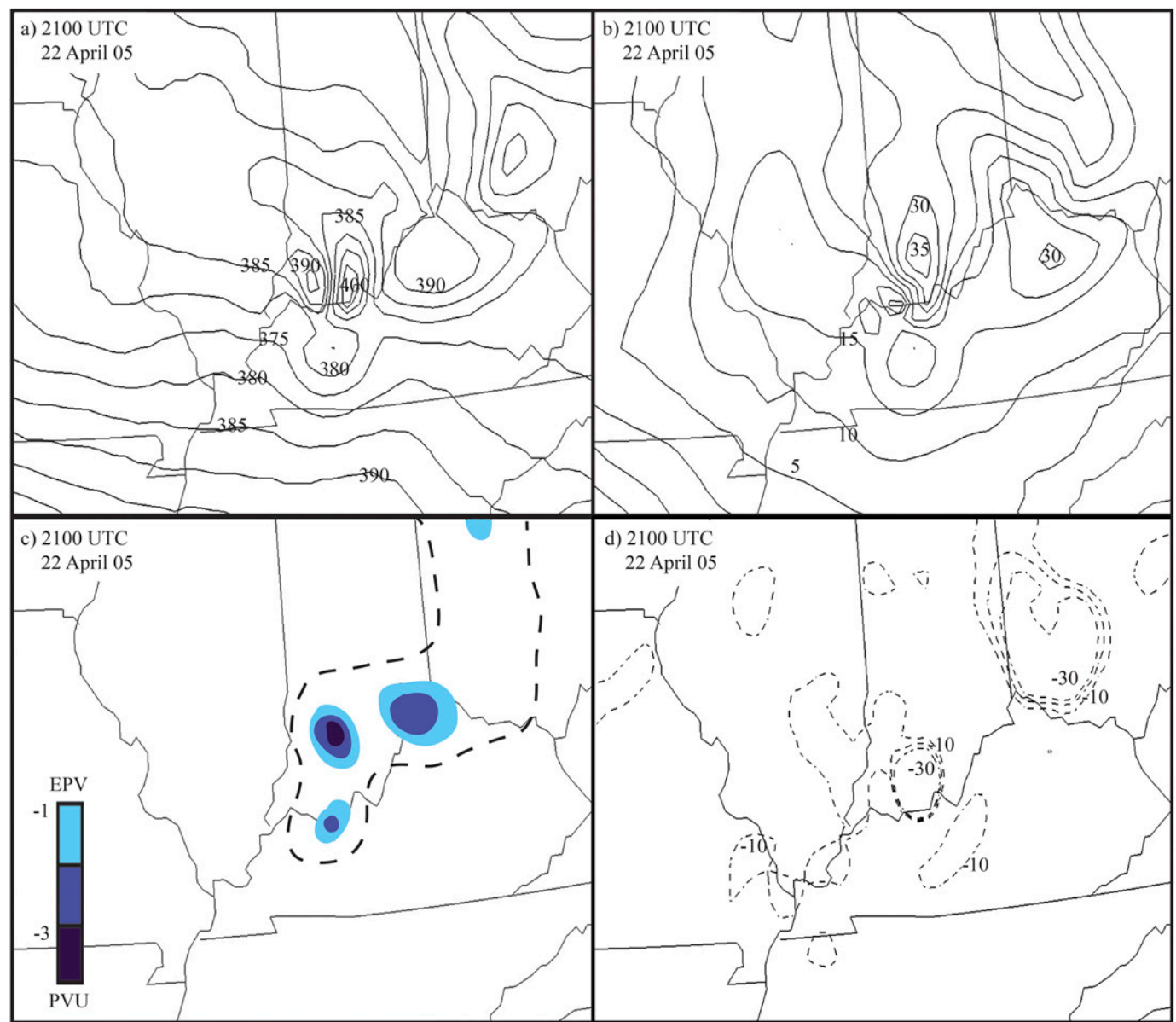

FIG. 10. Plan views at $10.9 \mathrm{~km}$ of dynamical quantities for the jet flare-ups at 2100 UTC 22 Apr 2005: (a) angular momentum (divided by $a \cos \varphi$; interval: $375-400 \mathrm{~m} \mathrm{~s}^{-1}$ ) (b) wind speed (contour interval: $5 \mathrm{~m} \mathrm{~s}^{-1}$ ), (c) strongly negative EPV (color bar; PVU), and (d) divergence (dashed contours every $10 \times 10^{-5} \mathrm{~s}^{-1}$ in the range from $-30 \times$ $10^{-5}$ to $\left.-10 \times 10^{-5} \mathrm{~s}^{-1}\right)$. The thick dashed line in $(\mathrm{c})$ encloses the region of inertial instability $(\mathrm{EPV}<0)$.

As in Fig. 2, Fig. 9 displays jet intensification for case 2 as depicted by the $350 \mathrm{~m} \mathrm{~s}^{-1}$ isosurface of angular momentum and the -1-PVU isosurface of EPV (viewed from the east), but with a threshold of $45 \mathrm{~m} \mathrm{~s}^{-1}$ for red shading of the angular momentum surface. At 1000 UTC 22 April 2005 (Fig. 9a), $10 \mathrm{~h}$ before the sequence shown in Fig. 8, regions of negative EPV (green isosurfaces) are found only in the warm moist lower troposphere along the cold front. Areas of inertial instability break out in the upper troposphere $\sim 10.5 \mathrm{~h}$ later (Figs. $9 \mathrm{~b}, 8 \mathrm{c}, \mathrm{d}$ ) in association with a poleward surge in the UTLS. The shape of the poleward-intruding angular momentum surface has narrowed, while the jet speed has increased beyond $45 \mathrm{~m} \mathrm{~s}^{-1}$. Another $1.5 \mathrm{~h}$ later, Figs. 9c, 6e, and 6f depict continued intensification, as the poleward extension of the angular momentum surface becomes even more pronounced in association with the poleward motion of inertially unstable air, and the region of high wind speed expands on the $350 \mathrm{~m} \mathrm{~s}^{-1}$ isosurface.
There is clear dynamical commonality between these two cases, characterized by a coincidence of inertial instability, poleward extension of angular momentum contours, and wind speed increase. There is also a commonality of jet flare-up behavior, which is now highlighted for case 2. Case 2 illustrates that jet accelerations can occur in association with moderate regions of inertial instability and that poleward momentum surges can occur at smaller spatial scales than in case 1 . Figure 10 shows the spatial coincidence at 10.9-km altitude of mesoscale regions of high absolute angular momentum, high wind speed (jet flare-ups), negative EPV, and regions of divergence at 2100 UTC 22 April 2005. In Figs. 10a and 10b, maxima in angular momentum and wind speed occur over southern Indiana and southern Ohio, with a minimum over northern Kentucky. These features are intimately intertwined with regions of significant inertial instability (Fig. 10c) and divergence (Fig. 10d). Centers of 
horizontal convergence (Fig. 10d) are found just downstream of regions of strong inertial instability (Fig. 10c) and near the total wind speed maxima (Figs. $10 \mathrm{a}, \mathrm{b})$. This is consistent with signatures expected from inertial instability, where poleward acceleration gives rise to a momentum surge and convergence just poleward of the region of inertial instability.

Supplemental movie 2 highlights these jet flare-ups for the 48-h simulation, as seen from the southeast looking to the northwest over the Tennessee Valley region. In this sequence, upward- and poleward-moving streams of air with EPV $<0$ are shown in light gray while an isosurface of absolute momentum is shown in blue, with speeds exceeding $32 \mathrm{~m} \mathrm{~s}^{-1}$ shown in red. Note how the inertially unstable air interacts with the isosurface of momentum, resulting in several small, localized wind speed maxima.

\section{Conclusions}

This study explores the hypothesis that inertial instability can act as a prime mover and facilitate poleward displacement of a wind speed maximum. We have attempted to visualize the effects of inertial instability on synoptic-scale flows. Consistent with considerations of the horizontal momentum equations following the motion, it is found that inertial instability leads to 1 ) acceleration of poleward motion, followed by 2) acceleration of the zonal flow. That is, inertial instability can cause a poleward displacement of the jet maximum. An idealized diagram of this sequence is shown in Fig. 11. The perturbation to the basicstate flow caused by inertial instability is on a convective time scale, with full evolution of the pulse occurring on the order of hours, a shorter time scale than the more slowly evolving large-scale flow. The quadrature relationship between meridional flow acceleration and zonal flow acceleration is to be expected from considering (1) under conditions of inertial instability, as borne out by the Lagrangian momentum budget along the curved path toward the top of the ridge.

At the beginning of a poleward surge, the Rossby number for meridional flow was quite high, indicating that adjustment processes were very strong with regard to the meridional flow, consistent with inertial instability as a primary causal agent. During the first half of the arc around the ridge, the meridional flow reached a maximum as the meridional acceleration became negative and the Rossby number for meridional flow relaxed toward geostrophic values. The second phase of the arc involved acceleration of the zonal flow in the jet flare-up phase, with concomitant increases in the Rossby number for zonal flow.

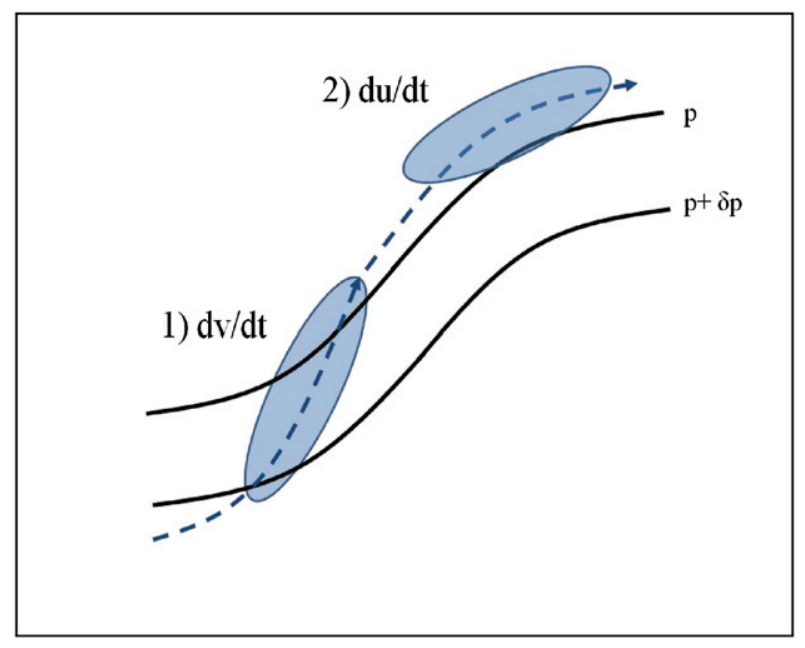

FIG. 11. Idealized diagram of the relationship between inertial instability and zonal jet flare-ups in the upper troposphere. In the inertially unstable stage 1 , the meridional flow accelerates down the meridional pressure gradient (two pressure contours shown) in the presence of weak zonal flow (negative ageostrophic flow). In stage 2 , the zonal flow accelerates because of the Coriolis torque on the strong meridional flow in the presence of a weak zonal pressure gradient. Inertial instability can facilitate poleward displacement of a zonal wind maximum and contribute to the shape of the ridge.

The anatomy of a poleward surge includes a core of highly inertially unstable air, with a head of high angular momentum and high zonal wind speed. It appears as a poleward-extruding bubble of high angular momentum backed by inertially unstable air across a range of scales (cases 1 and 2). It may be of interest to compare hydrostatic and geostrophic balance. In hydrostatic balance, the gravitational and the vertical pressure gradient forces are of order $10 \mathrm{~m} \mathrm{~s}^{-2}$, with vertical accelerations in thunderstorms being more than an order of magnitude smaller. Yet it is small negative values of $\partial \theta / \partial z$ that lead to deep convection, with a structure having a core of convective instability pushing convectively stable air above it upward. The pressure gradient and Coriolis terms in geostrophic balance are typically on the order of $10^{-3} \mathrm{~m} \mathrm{~s}^{-2}$, with horizontal accelerations on the order of $10^{-4} \mathrm{~m} \mathrm{~s}^{-2}$. In an analogous fashion, small negative values of $f+\zeta$ can promote a poleward surge, with a structure having a core of inertial instability pushing air with high angular momentum poleward ahead of it.

Ciesielski et al. (1989) found that inertial instability can be significant along the edge of an upper-tropospheric ridge on the equatorward side of the subtropical jet. To the extent that upper-tropospheric anticyclones are composed of poleward-moving low-PV streamers (T. Palmer 2006, personal communication; Chagnon and Gray 2015), the natural poleward and eastward flow promoted by inertial instability may act as an important agent in 
creating and maintaining the shape of a ridge. It will be of interest to further explore the effects of inertial instability on the evolution of the wind and mass fields and on the excitation of gravity waves in developing midlatitude cyclones.

Acknowledgments. We are grateful for support from NASA Grant NNX10AG57G and NSF Grants AGS1256215 and AGS-1555851. We thank Greg Tripoli for helpful conversations and Pete Pokrandt and Kuniaki Inoue for lending their computing expertise. We would also like to acknowledge helpful reviews from Harald Richter and an anonymous reviewer.

\section{REFERENCES}

Angell, J. K., 1962: The influence of inertial instability upon transosonde trajectories and some forecast implications. Mon. Wea. Rev., 90, 245-251, doi:10.1175/1520-0493(1962)090<0245: TIOIIU $>2.0 . \mathrm{CO} ; 2$.

Blanchard, D. O., W. R. Cotton, and J. M. Brown, 1998: Mesoscale circulation growth under conditions of weak inertial instability. Mon. Wea. Rev., 126, 118-140, doi:10.1175/ 1520-0493(1998)126<0118:MCGUCO >2.0.CO;2.

Blumen, W., 1972: Geostrophic adjustment. Rev. Geophys., 10, 485-528, doi:10.1029/RG010i002p00485.

Cahn, A. J., 1945: An investigation of the free oscillations of a simple current system. J. Meteor., 2, 113-119, doi:10.1175/ 1520-0469(1945)002<0113:AIOTFO>2.0.CO;2.

Chagnon, J. M., and S. L. Gray, 2015: A diabatically generated potential vorticity structure near the extratropical tropopause in three simulated extratropical cyclones. Mon. Wea. Rev., 143, 2337-2347, doi:10.1175/MWR-D-14-00092.1.

Ciesielski, P. E., D. E. Stevens, R. H. Johnson, and K. R. Dean, 1989: Observational evidence for asymmetric inertial instability. J. Atmos. Sci., 46, 817-831, doi:10.1175/1520-0469(1989)046<0817: OEFAII $>2.0 . \mathrm{CO} ; 2$.

Dunkerton, T. J., 1981: On the inertial stability of the equatorial middle atmosphere. J. Atmos. Sci., 38, 2354-2364, doi:10.1175/ 1520-0469(1981)038<2354:OTISFT $>2.0$. CO 2 .

Eliassen, A., 1951: Slow thermally or frictionally controlled meridional circulation in a circular vortex. Astrophys. Norv., 5, 19-60.

- 1959: On the formation of fronts in the atmosphere. The Rossby Memorial Volume, Rockefeller Institute Press, 277-287.

—_, and E. Kleinschmidt, 1957: Handbuch der Physik. Vol. 48, Springer-Verlag, 154 pp.

Emanuel, K. A., 1979: Inertial instability and mesoscale convective systems. Part I: Linear theory of inertial instability in rotating viscous fluids. J. Atmos. Sci., 36, 2425-2449, doi:10.1175/ 1520-0469(1979)036<2425:IIAMCS >2.0.CO;2.

__ 1982: Inertial instability and mesoscale convective systems. Part II: Symmetric CISK in a baroclinic flow. J. Atmos. Sci., 39, 1080-1097, doi:10.1175/1520-0469(1982)039<1080: IIAMCS $>2.0$.CO;2.

Fritsch, J. M., and R. A. Maddox, 1981: Convectively driven mesoscale pressure systems aloft. Part I: Observations. J. Appl. Meteor., 20, 9-19, doi:10.1175/1520-0450(1981)020<0009: CDMWSA $>2.0 . \mathrm{CO} ; 2$.

Fritts, D. C., L. Yuan, M. H. Hitchman, L. Coy, E. Kudeki, and R. F. Woodman, 1992: Dynamics of the equatorial mesosphere observed using the Jicamarca MST radar during June and August 1987. J. Atmos. Sci., 49, 2353-2371, doi:10.1175/ 1520-0469(1992)049<2353:DOTEMO>2.0.CO;2.

Hayashi, H., M. Shiotani, and J. C. Gille, 1998: Vertically stacked temperature disturbances near the equatorial stratopause as seen in cryogenic limb array etalon spectrometer data. J. Geophys. Res., 103, 19469-19483, doi:10.1029/ 98JD01730.

Hitchman, M. H., C. B. Leovy, J. C. Gille, and P. L. Bailey, 1987: Quasi-stationary zonally asymmetric circulations in the equatorial middle atmosphere. J. Atmos. Sci., 44, 2219-2236, doi:10.1175/1520-0469(1987)044<2219:QSZACI >2.0.CO;2.

Holton, J. R., 2006: An Introduction to Dynamic Meteorology. Academic Press, 535 pp.

Jascourt, S., 1997: Convective organizing and upscale development processes explored through idealized numerical experiments. Ph.D. dissertation, Dept. of Atmospheric and Oceanic Sciences, University of Wisconsin-Madison, $267 \mathrm{pp}$.

Keyser, D. A., and D. R. Johnson, 1984: Effects of diabatic heating on the ageostrophic circulation of an upper tropospheric jet streak. Mon. Wea. Rev., 112, 1709-1724, doi:10.1175/ 1520-0493(1984)112<1709:EODHOT>2.0.CO;2.

Koch, S. E., and P. B. Dorian, 1988: A mesoscale gravity wave event observed during CCOPE. Part III: Wave environment and probable source mechanisms. Mon. Wea. Rev., 116, 2570-2592, doi:10.1175/1520-0493(1988)116<2570:AMGWEO>2.0.CO;2.

Kocin, P. J., W. Uccellini, and R. A. Peterson, 1986: Rapid evolution of a jet streak circulation in a pre-convective environment. Meteor. Atmos. Phys., 35, 103-138, doi:10.1007/BF01026169.

Maddox, R. A., 1980: Mesoscale convective complexes. Bull. Amer. Meteor. Soc., 61, 1374-1387, doi:10.1175/1520-0477(1980)061<1374: $\mathrm{MCC}>2.0 . \mathrm{CO} ; 2$.

__, 1983: Large-scale meteorological conditions associated with midlatitude convective complexes. Mon. Wea. Rev., 111, 1475-1493, doi:10.1175/1520-0493(1983)111<1475: LSMCAW $>2.0 . \mathrm{CO} ; 2$.

McCann, D. W., 2001: Gravity waves, unbalanced flow, and aircraft clear air turbulence. Natl. Wea. Dig., 25 (1-2), 3-14.

Mecikalski, J. R., and G. J. Tripoli, 1998: Inertial available kinetic energy and the dynamics of tropical plume formation. Mon. Wea. Rev., 126, 2200-2216, doi:10.1175/ 1520-0493(1998)126<2200:IAKEAT > 2.0.CO;2.

$\longrightarrow$, and - 2003: Influence of upper-tropospheric inertial instability on the convective transport of momentum. Quart. J. Roy. Meteor. Soc., 129, 1537-1563, doi:10.1256/qj.00.08.

Namias, J., and P. F. Clapp, 1949: Confluence theory of the high tropospheric jet stream. J. Meteor., 6, 330-336, doi:10.1175/ 1520-0469(1949)006<0330:CTOTHT>2.0.CO;2.

Ninomiya, K., 1971: Mesoscale modification of synoptic situations from thunderstorm development as revealed by ATS III and aerological data. J. Appl. Meteor., 10, 1103-1121, doi:10.1175/ 1520-0450(1971)010<1103:MMOSSF > 2.0.CO;2.

Palmén, E., and C. W. Newton, 1969: Atmospheric Circulation Systems: Their Structure and Physical Interpretation. International Geophysics Series, Vol. 13, Academic Press, 603 pp.

Pokrandt, P. J., G. J. Tripoli, and D. D. Houghton, 1996: Processes leading to the formation of mesoscale waves in the midwest cyclone of 15 December 1987. Mon. Wea. Rev., 124, 2726-2752, doi:10.1175/1520-0493(1996)124<2726: PLTTFO $>2.0 . \mathrm{CO} ; 2$.

Rossby, C.-G., 1938: Solenoidal circulations resulting from lateral mixing. Eos, Trans. Amer. Geophys. Union, 19, 159-162, doi:10.1029/TR019i001p00159. 
Rowe, S. M., and M. H. Hitchman, 2015: On the role of inertial instability in stratosphere-troposphere exchange in midlatitude cyclones. J. Atmos. Sci., 72, 2131-2151, doi:10.1175/ JAS-D-14-0210.1.

Schumacher, R. S., D. M. Schultz, and J. A. Knox, 2010: Convective snowbands downstream of the Rocky Mountains in an environment with conditional, dry symmetric, and inertial instabilities. Mon. Wea. Rev., 138, 4416-4438, doi:10.1175/ 2010MWR3334.1.

Shapiro, M. A., 1981: Frontogenesis and geostrophically forced secondary circulations in the vicinity of jet stream-frontal zone systems. J. Atmos. Sci., 38, 954-973, doi:10.1175/ 1520-0469(1981)038<0954:FAGFSC $>2$ 2.0.CO;2.

Sutcliffe, R. C., 1938: On development in the field of barometric pressure. Quart. J. Roy. Meteor. Soc., 64, 495-504, doi:10.1002/ qj. 49706427614.
Tripoli, G. J., 1992a: An explicit three-dimensional nonhydrostatic numerical simulation of a tropical cyclone. Meteor. Atmos. Phys., 49, 229-254, doi:10.1007/BF01025409.

- 1992b: A nonhydrostatic numerical model designed to simulate scale interaction. Mon. Wea. Rev., 120, 1342-1359, doi:10.1175/ 1520-0493(1992)120<1342:ANMMDT>2.0.CO;2.

Uccellini, L. W., and D. R. Johnson, 1979: The coupling of upper and lower jet streaks and implications for the development of severe convective storms. Mon. Wea. Rev., 107, 682-703, doi:10.1175/1520-0493(1979)107<0682:TCOUAL >2.0.CO;2.

Van Tuyl, A. H., and J. A. Young, 1982: Numerical simulation of a nonlinear jet streak adjustment. Mon. Wea. Rev., 110, 2038-2054, doi:10.1175/1520-0493(1982)110<2038:NSONJS>2.0.CO;2.

Zhang, F., S. E. Koch, C. A. Davis, and C. L. Kaplan, 2000: A survey of unbalanced flow diagnostics and their application. $A d v$. Atmos. Sci., 17, 165-183, doi:10.1007/s00376-000-0001-1. 